\title{
Study on Risks in Marine Management and their Administrative Governance
}

\author{
Shufen Liu, Jingyi Zhang, Wei Xu \\ National Ocean Technology Center, Tianjin 300112, China \\ 海洋管理中的风险和行政规制探讨 \\ 刘淑芬, 张静怡, 徐伟 \\ 国家海洋技术中心, 天津 300112, 中国
}

\begin{abstract}
With the increasing development and utilization of marine resources, the risks in marine management are increasing. Based on the relationship between causes and human behaviors, this paper analyzes the risks arising from natural and human activities in marine management in China, and analyzes the causes. This paper holds that the risks in marine management are characterized by heterogeneity, sensitivity, wholeness and global. Regarding marine management risks and risk characteristics, this paper discusses the administrative governance of marine risks, including the governance of law-policy levels, optimization of the management system and mechanism, scientific planning of resource development, and clarification of risk responsibility undertakers.
\end{abstract}

Keywords: risk; marine management; administrative governance

\section{摘要}

随着人类越来越多的开发利用海洋资源, 海洋 管理中的风险日增。本文根据风险成因与人类行为 的关系, 分析了我国海洋管理中来自自然和人类活 动的各种风险, 并对其成因进行了分析研究。认为 海洋管理中的风险具有杂性、敏感性、整体性和全 球性的特点。针对海洋管理中风险及其特点, 探讨 了海洋风险的行政规制途径, 包括法律和政策层面 规制、优化管理体制机制、资源开发的科学规划和 明确风险主体责任。
关键词: 风险; 海洋管理; 行政规制

1. 引言

\section{1. 风险行政法的兴起和发展}

风险是指可能发生的危险。随着人类社会的进 步, 科技的发展, 现代社会所探讨的风险与传统社 会中的风险相比, 其包含的内容已扩展了许多。传 统的风险更多来自于自然, 如洪涝灾害、雪灾、旱 灾等各种自然灾害, 以及因自然因素引发的可能发 生于个体的危险。随着人类社会的进步, 风险所包 含的内容不断扩展, 交通事故、食品安全、大气污 染、生态破坏等, 这些风险更多的是因为技术进步、 经济发展、资源开发等人类自身活动而产生。

伴随人类社会风险的增加, 特别是因人类自身 行为而产生的风险的剧增, 风险的规制研究已引起 越来越多的学者、管理者的重视。而作为对规范公 民行为的最重要、最常见的手段, 行政规制在该领 域的作用得到了广泛认同, 风险行政法在世界范围 内随之兴起并迅速发展。

20 世纪后半期, 最先对 “社会风险” 深入研 究的学者是乌尔里希 - 贝克(Ulrich Beck), 之后吉 登斯、卢曼、拉什等也对社会风险进行了探讨, 其 研究侧重于风险的不确定性和损失性。伊丽莎白 费雪研究了风险规制于行政宪政主义。珍妮弗斯 蒂尔研究了风险于法律理论。史蒂芬 布雷耶对政 府如何有效规制风险进了研究。我国的金自宁风险 对行政法的理论问题进行了研究 ${ }^{[1][2]}$ 。沈崩以食品 安全领域的管理为例对风险行政法进行了研究 ${ }^{[3]}$ 。 郭燕、闰洪升对金融领域中的法律风险和规制管理 进行了研究。吴宗之等对一定时间段内中国和美国 
三次产业事故风险进行了分析研究 ${ }^{[4]}$ 。

\section{2. 海洋行政管理风险规制研究现状}

相对其他领域的风险管理, 海洋管理领域的风 险和风险行政规制研究极少, 笔者用 “行政规制” 综合检索万方数据库, 共检索到 11852 条结果, 在 结果中检索 “海洋” 关键词, 仅有 1 条结果, 是 “我 国海洋油污污染刑事追究之困境”, 也并非研究风 险规制; 用 “风险规制” 检索, 共有 3049 条结果, 在结果中检索 “海洋” 关键词, 结果为零; 用 “海 洋管理” 检索, 共有 28156 条结果, 在结果中检索 “风险” 关键词, 仅有 56 条结果, 大部分与海上 油气、工程项目、船舶等相关。可见, 目前关于海 洋行政管理风险和风险的行政规制研究极少。

\section{3. 海洋管理中的风险规制研究的必要性}

随着陆地资源的消耗和人类科技水平提升, 人 类针对海洋的活动越来越多, 伴随出现的风险数量 和风险类型剧增, 从管理者和规制的角度研究海洋 风险类型、规制途径, 对于人类开发利用海洋资源, 减少和降低开发利用过程中的自身风险和损失, 是 风险理论研究也是行政规制研究的重要课题和领 域。鉴于目前该领域研究基础的薄弱, 该领域的相 关研究参考极少, 本文拟对研究中的基本问题风险 类型及其规制途径进行讨论。

\section{2. 我国海洋管理中的风险}

按上文的分类, 根据其成因与人类行为的关 系, 我们将风险分为来自于自然的风险和来自于人 类行为的风险。

\section{1. 来自于自然的风险}

海洋是全球气候系统中的一个重要环节, 通过 与大气的能量物质交换和水循环等作用在调节和 稳定气候上发挥着决定性作用, 是地球气候的 “调 节器”。因此, 与气象气候相关的风险相对较多, 其造成的损失也最大。《中国海洋灾害公报》中统 计的就有 10 多种, 包括风暴潮、海浪、海冰、海 啸、赤潮、绿潮、海平面变化、海岸侵蚀、海水入 侵与土壤盐渍化、咸潮入侵等, 其中, 最主要的灾 害是风暴潮, 其造成的直接经济损失往往占我国海 洋灾害直接经济损失的 $90 \%$ 以上。根据《中国海洋 灾害公报》统计, 近 5 年来, 海洋灾害造成直接经 济损失最大的一年是 2013 年, 约为 163.48 亿元, 其中风暴潮造成的直接损失约为 153.67 亿元, 占 全部经济损失的 $94 \% ; 2014$ 年风暴潮造成的直接
经济损失比重最大, 占全部海洋灾害直接经济损失 的 $99.7 \%$ 。

\section{2. 来自于人类活动的风险}

全球大洋相通, 海洋蕴含无数的资源宝藏, 限 于人类科技水平发展, 以及人类长期以来以陆地为 生活居住的主要场所, 人类对海洋资源的开发相对 于陆地极少, 但随着陆地资源的日益耗竭, 海洋资 源的重要性凸显。人类针对海洋资源的开发利用活 动以及伴随的风险增加。这些风险往往具有复杂 性、敏感性、整体性和全球性等特点。

海洋环境污染和生态破坏。造成海洋环境污 染和生态破坏的主要原因一是陆地向海洋排放污 水, 包括直接向海洋排放的污水, 以及流入海中的 河流携带的污水。二是带有污染物的废气排放到大 气中,形成酸雨后, 造成降雨进入海中。三是过度捕 捞和开采海洋资源,破坏了海洋的生态平衡。四是 人类在海洋资源开发利用过程中排放的废弃物, 造 成的污染物泄露、有机物泄露等。其中最主要的是 陆源污染物的排放, 海洋环境污染的主要来源是陆 源污染已得到了广泛共识。联合国环境规划署在为 蒙特利尔环境部长会议预备的一份报告中指出, $80 \%$ 的海洋污染源于陆源污染。

由于海洋具有自净能力, 以及人类的主要活动 场所是陆地而不是海洋, 所以, 长期以来, 人们把 大部分的污染物都排向海洋。除了对当地造成海水 质量下降、赤潮、绿潮、海洋生物灭绝等直接可见 的后果外, 由于海水的流动性和全球大洋的相通, 这些污染物可以通过洋流扩散到全球, 而随着海洋 生物食物链, 海洋环境污染最终又回到人类体内, 无论距离污染排放地有多远，包括罕有人类活动的 极地地区, 如 2018 年我国第 34 次南极考察队的科 学家们在南极海域的海水中发现了微塑料的存在。

海洋权益和国际关系。陆地资源的耗竭使得 人们越来越重视海洋资源开发。历史上不受重视的 海洋国土已成了国际关系的敏感点。基于各国海洋 权益产生的风险不容忽视, 如中国南海地区的石油 资源开发，挪威和冰岛两国的 “鲟鱼大战”, 日本 和俄罗斯的 “渔业战争”，法国与西班牙两国渔民 的对峙和枪战等。

全球贸易和地区安全。经济的全球化导致国 际航运业的扩展, 而伴随国际航运业的发展, 国际 航运的安全问题一直是人们关注的重点之一, 其风 险除了来自于自然因素外, 来自于地区安全的风险 不容忽视。在航次租船合同中, 大部分标准租船格 
式合同中都包含关于海盗、战争风险的条款。印度 尼西亚、尼日利亚、菲律宾、索马里及亚丁湾海域 已成为暴力海盜和武装抢劫频发的热点区域, 紧随 其后的分别为哥伦比亚、莫桑比克、刚果河区域。 许多国家甚至已开展了针对本国船只的海外军事 护航行动, 如 2008 年底开始中国海军在亚丁湾索 马里海盗频发海域开展了中国海军护航。

\section{3. 海洋管理风险的行政规制路径}

针对海洋管理中的风险因素, 其规制途径有许 多中, 除了上文提到的针对海盗行为的军事护航 外, 最重要的手段就是行政规制, 特别是对于国内 的海洋管理。具体包括法律和政策层面的规制、优 化管理体制机制、资源开发的科学规划和明确风险 主体责任。

\section{1. 法律和政策层面的规制}

法律是一种社会行为规范。由国家制定或认 可, 并以国家强制力保证实施, 具有强制性, 对全 体社会成员具有普遍约束力。法律以法律条文的形 式明确告知人们, 什么是可以做的, 什么是不可以 做的, 哪些行为是合法的, 哪些行为是非法的。违 法行为将通过法律的强制执行力得到矫正。法规和 管理部门出台的规章政策具有类似效果, 但其法律 效力稍低。

通过立法和出台管理政策, 可以使得人们针对 海洋的海洋开发利用活动以及相关的在海上的活 动有明确的预期和判断, 从而调整自己的行为, 减 少和降低对海洋环境的影响和破坏。立法和出台政 策的规制手段对于养殖、围填海、矿产资源开发等 在海上开展的活动, 以及污染物排放等活动具有明 显的和直接的效果。

由于海洋环境影响的全球性和整体性, 国内的 立法和政策出台往往会收到国际条约的限制和影 响。如《联合国海洋法公约》等。

\section{2. 优化管理体制机制}

作为人类活动区域, 海洋管理具有涉及行业 多、部门多, 陆地上的许多行业领域在海上均有延 伸, 如渔业、交通运输、矿产开采、地质调查等。 在空间范围上, 陆地和海洋界限不明显, 如我国的 行政管理界限于自然的海陆分界线不同, 此外, 部 分滩涂有淤涨, 海陆的自然分界线处于变动中。在 管理上, 陆地管理和海洋管理密不可分, 最典型的 例子是陆源污染物的排放, 此外还有沿海区域的开 发, 往往也需要陆海统筹。因此, 科学合理的海洋
行政管理体制机制是规制海洋风险的一个重要途 径。

中国一直在优化海洋管理体制机制方面进行 了探索。自上世纪 80 年代以来, 中国已进行了 7 次国务院政府机构改革。2018 年 3 月 13 日, 中国 公布了最新的机构改革方案, 其中就有关于自然资 源部的组建体现了对海洋管理体制的优化。自然资 源部组建后, 将从国土空间整体层面实现对海洋资 源的用途管制和生态保护修复, 减少和降低海洋污 染、生态破坏、海洋资源开发等的风险规制问题。 如陆源污染物排放、海岸带规划和近岸海域开发将 不再存在部门海陆不同部门间的协调问题。

\section{3. 资源开发的科学规划}

海洋管理中许多风险都是由于盲目的不科学 的开发利用活动造成的, 而规划是保证资源开发利 用活动科学合理的最有效的手段。中国早在上世纪 80 年代就开始了海洋功能区划的研究, 力图通过 海域的地理位置、自然资源状况、自然环境条件和 社会需求等因素而划分的不同的海洋功能类型区, 用来指导、约束海洋开发利用实践活动, 保证海上 开发的经济、环境和社会效益 ${ }^{[5][6]}$ 。之后的全国主 体功能区规划、海洋主体功能区规划均体现了管理 部门对规划的重视, 以及规划在海洋管理中的应 用。事实证明, 虽然规划并非是管理部门进行海洋 管理风险规制的初衷, 但科学的规划在中国海洋管 理风险规制中取得了很好效果 ${ }^{[7]}$, 有效的遏制了海 洋环境的恶化, 规范了海洋资源开发利用秩序。

\section{4. 明确风险主体责任}

对于某些海洋开发利用活动而言, 如海底油气 管道, 其风险具有特殊性, 其运行过程中的安全是 用海人和管理者关注的重点, 管道破坏和油气泄漏 不仅会对管道所有者带来严重损失, 还会污染海洋 环境，而威胁其安全的风险不仅来自管道自身的正 常维护, 还有附近海域的开发利用。因此, 如何界 定风险管理主体的责任, 对于调动风险主体的积极 性主动性, 进行风险管理, 降低风险具有至关重要 的意义。从行政管理的角度立法或出台政策, 在法 律和政策中明确各主体的责任, 是最有效最直接的 方式和途径。

4. 结论

综上所述, 由于海洋不同于陆地的特点, 海洋 管理中风险具有不仅存在自然风险, 还有不同于大 多数陆地上人类行为造成的风险的复杂性、整体性 
和全球性特点, 相应的风险的行政规制途径也与其 他领域有所差别。进行风险规制时, 必须进行综合、 全面的风险分析和调研, 结合不同海洋管理风险的 成因和特点, 以及风险发生的空间位置, 综合比较 不同的方式, 确定最佳的风险规制途径, 建立科学 合理的风险防范体系, 将风险损失降到最低。

\section{参考文献}

[1] 金自宁. 风险行政法研究的前提问题. 华东政 法大学学报,2014, (1):4-12.

[2] 金自宁. 风险中的行政法. 法律出版社, 北京, 2014 年 8 月.

[3] 沈岁. 食品安全、风险治理与行政法. 北京大 学出版社, 北京, 2018 年 1 月.

[4] Wu Z Z, Zhang S Z, Zeng M R. Analytical research on the accident risk in three industries of China and USA in the period of 2006-2010. Journal of Risk Analysis and Crisis Response, 2013, 3(1):52-58.

[5] 刘淑芬,徐伟, 侯智洋, 岳奇. 海洋功能区划管控 体系研究. 海洋环境科学, 2014(3):455-458.

[6] 徐伟,刘淑芬. 全国海洋功能区划实施评价研 究. 海洋环境科学, 2014, (3): 466-471.

[7] 夏登文, 徐伟,刘淑芬. 全国海洋功能区划实施 评价,中国海洋出版社, 北京,2013 年. 